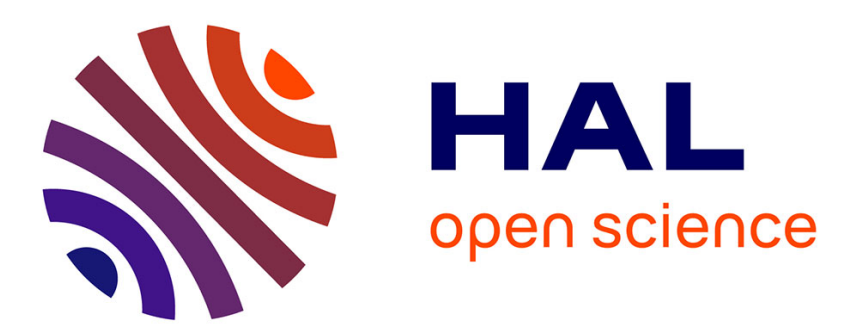

\title{
Application of multireflection grazing incidence method for stress measurements in polished Al-Mg alloy and CrN coating
}

Marianna Marciszko, A Baczmanski, K Wierzbanowski, M Wróbel, Chedly Braham, J.-P. Chopart, A Lodini, J Bonarski, L. Tarkowski, N Zazi

\section{To cite this version:}

Marianna Marciszko, A Baczmanski, K Wierzbanowski, M Wróbel, Chedly Braham, et al.. Application of multireflection grazing incidence method for stress measurements in polished $\mathrm{Al}-\mathrm{Mg}$ alloy and CrN coating. Applied Surface Science, 2012, 266, pp.256-267. 10.1016/j.apsusc.2012.12.005 . hal00991108

\section{HAL Id: hal-00991108 https://hal.science/hal-00991108}

Submitted on 14 May 2014

HAL is a multi-disciplinary open access archive for the deposit and dissemination of scientific research documents, whether they are published or not. The documents may come from teaching and research institutions in France or abroad, or from public or private research centers.
L'archive ouverte pluridisciplinaire HAL, est destinée au dépôt et à la diffusion de documents scientifiques de niveau recherche, publiés ou non, émanant des établissements d'enseignement et de recherche français ou étrangers, des laboratoires publics ou privés. 




\section{Science Arts \& Métiers (SAM)}

is an open access repository that collects the work of Arts et Métiers ParisTech researchers and makes it freely available over the web where possible.

This is an author-deposited version published in: http://sam.ensam.eu

Handle ID: .http://hdl.handle.net/10985/8134

\section{To cite this version :}

Marianna MARCISZKO, A BACZMANSKI, K WIERZBANOWSKI, M WRÓBEL, CHEDLY BRAHAM, J.-P. CHOPART, A LODINI, J BONARSKI, L. TARKOWSKI, N ZAZI - Application of multireection grazing incidence method for stress measurements in polished Al-Mg alloy and CrN coating - Applied Surface Science - Vol. 266, p.256-267 - 2012 




\section{Science Arts \& Métiers (SAM)}

is an open access repository that collects the work of Arts et Métiers ParisTech researchers and makes it freely available over the web where possible.

This is an author-deposited version published in: http://sam.ensam.eu

Handle ID: .http://hdl.handle.net/null

\section{To cite this version :}

Marianna MARCISZKO, A BACZMANSKI, K WIERZBANOWSKI, M WRÓBEL, CHEDLY BRAHAM, J.-P. CHOPART, A LODINI, J BONARSKI, L. TARKOWSKI, N ZAZI - Application of multireection grazing incidence method for stress measurements in polished Al-Mg alloy and CrN coating - Applied Surface Science - Vol. 266, p.256-267 - 2012 


\title{
Application of multireflection grazing incidence method for stress measurements in polished $\mathrm{Al}-\mathrm{Mg}$ alloy and $\mathrm{CrN}$ coating
}

\author{
M. Marciszko a , A. Baczmański a,*, K. Wierzbanowski ${ }^{a}$, M. Wróbel $^{\mathrm{a}}$, C. Braham ${ }^{\mathrm{b}}$, J.-P. Chopart ${ }^{\mathrm{c}}$, A. Lodini $^{\mathrm{c}}$, \\ J. Bonarski ${ }^{\mathrm{d}}$, L.Tarkowski ${ }^{\mathrm{d}}$, N. Zazi ${ }^{\mathrm{c}, \mathrm{e}}$ \\ a AGH University of Science and Technology,WFiIS and WIMiIP, al. A. Mickiewicza 30, 30-059 Kraków, Poland \\ b Arts et Métiers ParisTech (ENSAM), PIMM, 151, Bd de l'Hôpital 75013, Paris, France \\ ${ }^{\mathrm{c}}$ LISM EA 4695 UFR SEN, BP1039, Université de Reims Champagne Ardenne, Moulin de la Housse, 51687 Reims, Cedex, France \\ d Institute of Metallurgy and Materials Science, Polish Academy of Sciences, ul. Reymonta 25, 30-059 Kraków, Poland \\ e LMSE, Dépt de Génie Mécanique, Université Mouloud Mammeri, 15000 Tizi Ouzou, Algeria
}

\section{Keywords:}

Thin film

Residual stresses

X-ray diffraction

Grazing incidence method

Göbel mirror

\section{A B S T R A C T}

Multi-reflection grazing incidence geometry, referred to as MGIXD, characterized by a small and constant incidence angle, was applied to measure low surface stresses in very thin layers of Al-Mg alloy and CrN coating. These two materials were selected in order to deal with the low and high levels of residual stress, respectively. The influence of different mechanical treatments on residual stresses was studied for $\mathrm{Al}-\mathrm{Mg}$ samples. It was found that both rolling and mechanical polishing influence the distribution and amplitude of residual stress in surface layers. In the case of $\mathrm{CrN}$ coating, a very high compressive stress was generated during the deposition process. The stress distributions determined by the MGIXD method is in good agreement with the classic $\sin ^{2} \psi$ technique results for all studied samples. In performing stress measurements for a powder sample, it was found that the application of the Göbel mirror in the incident beam strongly reduces statistical and misalignment errors. Additionally, the root mean square values of the third order lattice strain within diffracting grains were determined.

\section{Introduction}

Both the magnitude and the spatial distribution of residual stress play key roles in the behaviour of materials subjected either to heat treatment or plastic deformation. The residual stress influences the fatigue response of solids, stress corrosion, and is important for the manufacturing process of all products. Depending on its direction and magnitude, the residual stress superimposed with an external load can be destructive or beneficial to a component. For example, the mechanical strength of a surface layer is improved by machining, which creates a compressive residual stress. The same type of stress increases fracture resistance and minimises spalling of the coating. The opposite type of stress, tensile residual stress, can accelerate the growth of the crack and cause the coating's destruction, when external loads are superimposed.

Diffraction methods are commonly used for determining lattice elastic deformation and distortion (i.e., of macrostrains and microstrains) from the displacement and broadening of the diffraction peak [1-4]. The stress present in the near surface volume can be measured using the standard X-ray $\sin ^{2} \psi$ method.

* Corresponding author. Tel.: +48 126172994; fax: +48126340010

E-mail address: baczman@ftj.agh.edu.pl (A. Baczmański).
However, this method is not advisable for the analysis of the in-depth stress gradient, because the penetration depth of X-ray radiation varies significantly during measurement. Therefore, the grazing incidence X-ray diffraction geometry (GIXD) was applied to measure residual stresses in thin surface layers [5-12]. In this work one of the version of the GIXD method referred to as the multi-reflection grazing incidence X-ray diffraction (MGIXD, [10-12]) was used in the laboratory diffractometer equipped with the Göbel mirror in the incident beam optics. Using this method, it is possible to perform a non-destructive stress analysis for different (and well defined) volumes below the surface of the sample and the stress can be measured at very shallow depths of a few micrometers. The main advantage of this method is that apart from the residual stress the root mean square of the lattice strain, caused by defects within polycrystalline material, can also be determined using Williamson-Hall method [13,14].

The disadvantage of the MGIXD method was its low accuracy in stress determination, when a classic line focus and a parallel plate collimator in the reflected beam optics were used in the measurement. For example the systematic error of about $50 \mathrm{MPa}$ for Fe powder was reported in [10] (this value corresponds to $20 \mathrm{MPa}$ if the Al elastic constants are used in the analysis). This is why our previous measurements were performed only for samples with high surface stresses $[10,11]$. Recently, the accuracy was considerably 
improved using the Göbel mirror to collimate an incident beam. A perfectly collimated parallel beam radically decreases the uncertainty of the determined peak position and, consequently, one reaches the accuracy of a few MPa for an Al powder sample. Due to very good precision and high beam intensity, the new experimental setup can be applied to measure low surface stresses in thin layers.

The reproducibility of the experimental setup with the Göbel mirror was already tested repeating measurements for different powder specimens [12]. It was found that the difference between the stresses measured using the MGIXD method was smaller than $15 \mathrm{MPa}$ for the $\mathrm{Al}$ powder. This value can be considered as the uncertainty of measurements arising from misalignments of the diffractometer and the sample position. From the measurements on the powder samples and also from theoretical analysis it was found that the important source of systematic error is the shift of $2 \theta$ zero value. The misalignment of the diffractometer equal to $\Delta 2 \theta=0.01^{\circ}$ leads to the fictitious stress of about $10-15 \mathrm{MPa}$ determined for the Al stress-free powder. This error can be minimised by the careful alignment of the diffractometer or the results obtained for the studied sample can be corrected by using the powder diffraction data.

The application of the MGIXD method is especially recommended for determining of the in-depth stress gradients close to the surface, which can significantly change the corrosion resistance of the material [15]. This methodology can be also used to determine the stress distribution in thin films. The latter stress influences the fracture and spalling resistance of the coating.

In the present work we demonstrate the possibilities of the MGIXD method on two examples of surface layers. The stress distribution is determined in a mechanically polished $\mathrm{Al}-\mathrm{Mg}$ alloy (isotropic elastic properties) and a $\mathrm{CrN}$ coating (anisotropic single crystal elastic constants).

\section{Experimental principles}

\subsection{Stress measurements using grazing incidence geometry}

The standard method for stress determination (called $\sin ^{2} \psi$ ) is based on the measurement of interplanar spacing for various directions of the scattering vector [1-3]. These directions are defined by $\phi$ and $\psi$ angles (Fig. 1a). Using diffraction, the mean interplanar spacing $\langle d(\phi, \psi)\rangle_{\{h k l\}}$, averaged over reflecting crystallites, is measured. As it has been mentioned, the orientation of the scattering vector varies in this method, however the reflecting plane index $\{h k l\}$ is kept constant during strain measurements. Consequently, different penetration depths of X-ray radiation appear for different tilt angles $\psi$ in standard geometry.

The multi-reflection grazing incidence geometry (MGIXD) is a non destructive diffraction method, which can be used to determine lattice elastic distortion in the near surface layers of a material. The characteristic feature of this method is a small and constant incidence angle [10-12]. Consequently, the penetration depth of X-ray radiation is well defined and does not change during the experiment. Measurements are performed for different sets of $\{h k l\}$ planes using the appropriate values of $2 \theta_{\{h k l\}}$ scattering angles. The incidence angle $\alpha$ is fixed during measurement, while the orientation of the scattering vector is characterized by the angle $\psi_{\{h k l\}}$. The $\psi_{\{h k l\}}$ angle depends on $h k l$ reflection ( $2 \theta_{\{h k l\}}$ angle) and on a constant incidence angle $\alpha$ (Fig. 1b):

$$
\{h k l\}=\theta_{\{h k l\}}-\alpha
$$

Consequently, possible values of $\psi_{\{h k l\}}$ angles are limited to the number of $h k l$ reflections used in the experiment.

In the case of the MGIXD method the measurements of interplanar spacings $\langle d(\phi, \psi)\rangle_{\{h k l\}}$ are performed in the near surface volume, which is limited by radiation absorption. To define this volume, the path of the X-ray beam through the sample must be considered (Fig. 1b). The measured average interplanar spacings $\langle d(\phi, \psi)\rangle_{\{h k l\}}$ are equal to:

$$
\begin{gathered}
<d(\phi, \psi)>_{\{h k l\}}=\frac{\int_{0}^{t} d(\phi, \psi, z)_{\{h k l\}} \exp [-\mu l(z)] d z}{\int_{0}^{t} \exp [-\mu l(z)] d z} \text { and } \\
l(z)=z\left(\frac{1}{\sin \alpha}+\frac{1}{\sin \left(2 \theta_{\{h k l\}}-\alpha\right)}\right)
\end{gathered}
$$

where $\mu$ is the linear coefficient of absorption and the above formula can be used if $\alpha » \alpha_{\mathrm{cr}}$ ( $\alpha_{\mathrm{cr}}$ is the critical angle for the total external reflection [2]), $z$ is a depth below the surface and the average is calculated over the volume of all reflecting grains in the beam path $l(z)=a(z)+b(z)$ (see Fig. 1b), i.e. from the surface $(z=0)$ to the thickness of the coating $(z=t)$. If the stresses are measured in a monolithic material or in a thick coating (comparing to penetration of $\mathrm{X}$-ray radiation) we assume that $t \rightarrow \infty$.

Eq. (2) is usually expressed in the equivalent form:

$$
\begin{gathered}
<d(\phi, \psi)>_{\{h k l\}}=\frac{\int_{0}^{t} d(\phi, \psi, z)_{\{h k l\}} \exp (-z / \tau) d z}{\int_{0}^{t} \exp (-z / \tau) d z} \text { and } \\
\tau=\left(\frac{\mu}{\sin \alpha}+\frac{\mu}{\sin \left(2 \theta_{\{h k l\}}-\alpha\right)}\right)^{-1}
\end{gathered}
$$

where "penetration depth" $\tau$ is defined as the distance from the sample surface, for which $(1-1 / e)=0.63$ part of total intensity of the incident beam is absorbed.

The above average corresponds to the so called "information" or "effective" depth $\bar{z}$, which can be understood as the mean value of $z$-depth weighted by an attenuation factor [8]:

$$
\bar{z}=\frac{\int_{0}^{t} z \exp (-z / \tau) d z}{\int_{0}^{t} \exp (-z / \tau) d z}=\left\{\begin{array}{cc}
\tau-\frac{t \exp (-t / \tau)}{1-\exp (-t / \tau)} & \text { forlimited } t \\
\tau & \text { for } t \rightarrow \infty
\end{array}\right.
$$

When small $\alpha$ angles are used (i.e., for long incident beam paths, i.e. $a(z) » b(z)$ in Fig. 1b) the penetration depth can be approximated by the expression $\tau=\sin \alpha / \mu$ (see Eq. (3)). Consequently both the penetration depth $\tau$ (Eq. (3)) and the information depth $\bar{z}$ (Eq. (4)) do not depend on $2 \theta$ and related $\psi$ (Eq. (1)) angles. The information depths $\bar{z}$ vs. $\sin ^{2} \psi$ calculated for the MGIXD and the standard method ( $\Omega$ mode $[1,2]$ ) are shown in Fig. 2 , where the materials studied in this work are considered. It is visible that only in the case of the MGIXD method, the information depth is almost constant for a fixed small $\alpha$ angle and for a large range of $\psi$ angle. Moreover, it is shown that stress can be measured for different layers under the sample surface by setting different $\alpha$ angle values (Fig. 2).

In the MGIXD method, the $\langle d(\phi, \psi)\rangle_{\{h k l\}}$ interplanar spacings are measured in the directions defined by $\phi$ and $\psi$ angles for different $h k l$ reflections. Hence, the orientations of the scattering vector with respect to the sample are strictly determined by Eq. (1), and the 


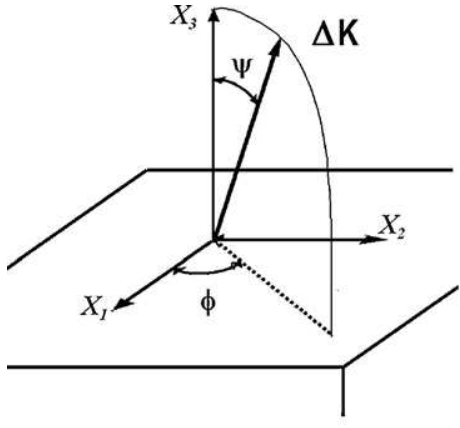

a)

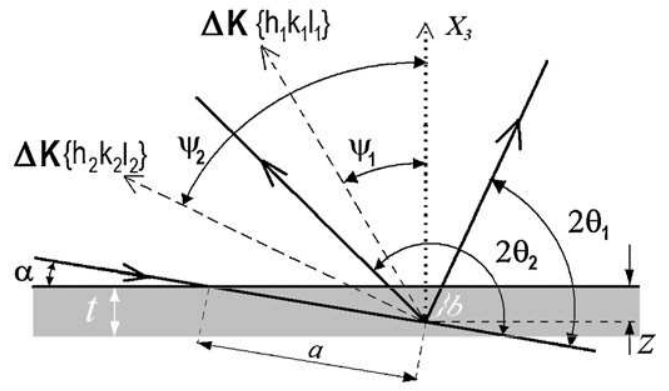

$l=a+b$

b)



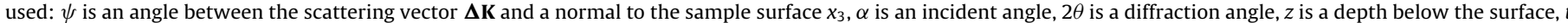
is the coating thickness and $l=a+b$ denotes length of the beam path in the sample.

measurements can be done only for a few $\psi$ angles. These experimental data can be easily analysed in a multi-reflection method, and the residual stress can be determined for every incidence angle $\alpha$ [10-12]. In this procedure, the equivalent lattice parameters are used (instead of $\langle d(\phi, \psi)\rangle_{\{h k l\}}$ ):

$<a(\phi, \psi)>_{\{h k l\}}=\sqrt{h^{2}+k^{2}+l^{2}}<d(\phi, \psi)>_{\{h k l\}}$

to determine the macrostress tensor. In the case of a quasiisotropic sample and when the forces perpendicular to the surface are equal to zero, the interplanar spacing measured in the direction of scattering vector ( $\Delta \mathbf{K}$ in Fig. 1a) is given by the well known relation $[3,11,12]$ :

$<a(\phi, \psi)>_{\{h k l\}}=\left[F_{i j}(h k l, \phi, \psi) \sigma_{i j}\right] a_{0}+a_{0}$,

where $\sigma_{i j}$ is the average macrostress for the information depth $\bar{z}$ (Eq. (4)) corresponding to a given incidence angle $\alpha$ (see Eq. (2)), $a_{0}$ is the strain free lattice parameter, while $F_{i j}(h k l, \phi, \psi)$ are the stress factors calculated for different $h \mathrm{kl}$ reflections related to different $\phi$ and $\psi$ angles [3].

In this work, the free-surface self-consistent method [3] was used to calculate the $F_{i j}(h k l, \phi, \psi)$ stress factors from single crystal elastic constants (given in Table 1 ) and experimentally determined crystallographic textures. It should be underlined that $F_{i j}(h k l, \phi, \psi)$ factors depend on the $h k l$ reflection, especially for crystals having
Table 1

Single crystal elastic constants of aluminium (used also for Al-Mg alloy AA5083) and CrN coating $[18,19]$.

\begin{tabular}{lllll}
\hline \multirow{2}{*}{ Material } & \multicolumn{2}{l}{ Single crystal elastic constants (GPa) } & Zener factor A \\
\cline { 2 - 5 } & $C_{11}$ & $C_{12}$ & $C_{44}$ & \\
\hline $\mathrm{Al}$ & 106.8 & 60.4 & 28.3 & 1.22 \\
$\mathrm{CrN}$ & 542 & 27 & 88 & 0.34 \\
\hline
\end{tabular}

high elastic anisotropy characterized by the Zener factor (also presented in Table 1 ):

$A=\frac{2 C_{44}}{C_{11}-C_{12}}$

Using the least square method for Eq. (6), the fitting parameters (i.e., $\sigma_{i j}$ and $a_{0}$ ) can be determined by minimizing a merit function given by formula [16]:

$\chi^{2}=\frac{1}{N-M} \sum_{n=1}^{N}\left(\frac{<a\left(\phi_{n}, \psi_{n}\right)>_{\{h k l\}}^{\exp }-<a\left(\phi_{n}, \psi_{n}\right)>_{\{h k l\}}^{c a l}}{\delta_{n}\left(<a(\phi, \psi)>_{\{h k l\}}\right)}\right)^{2}$

where $<a\left(\phi_{n}, \psi_{n}\right)>_{\{h k l\}}^{\exp }$ and $\left\langle a\left(\phi_{n}, \psi_{n}\right)>_{\{h k l\}}^{c a l}\right.$ are experimental and calculated equivalent lattice parameters determined using $h k l$ reflections, $\delta_{n}\left(\langle a(\phi, \psi)\rangle_{\{h k l\}}\right)$ is an experimental uncertainty of the spacing $<a\left(\phi_{n}, \psi_{n}\right)>\underset{\{h k l\}}{\exp }$ for the $n$-th measurement, $N$ and $M$
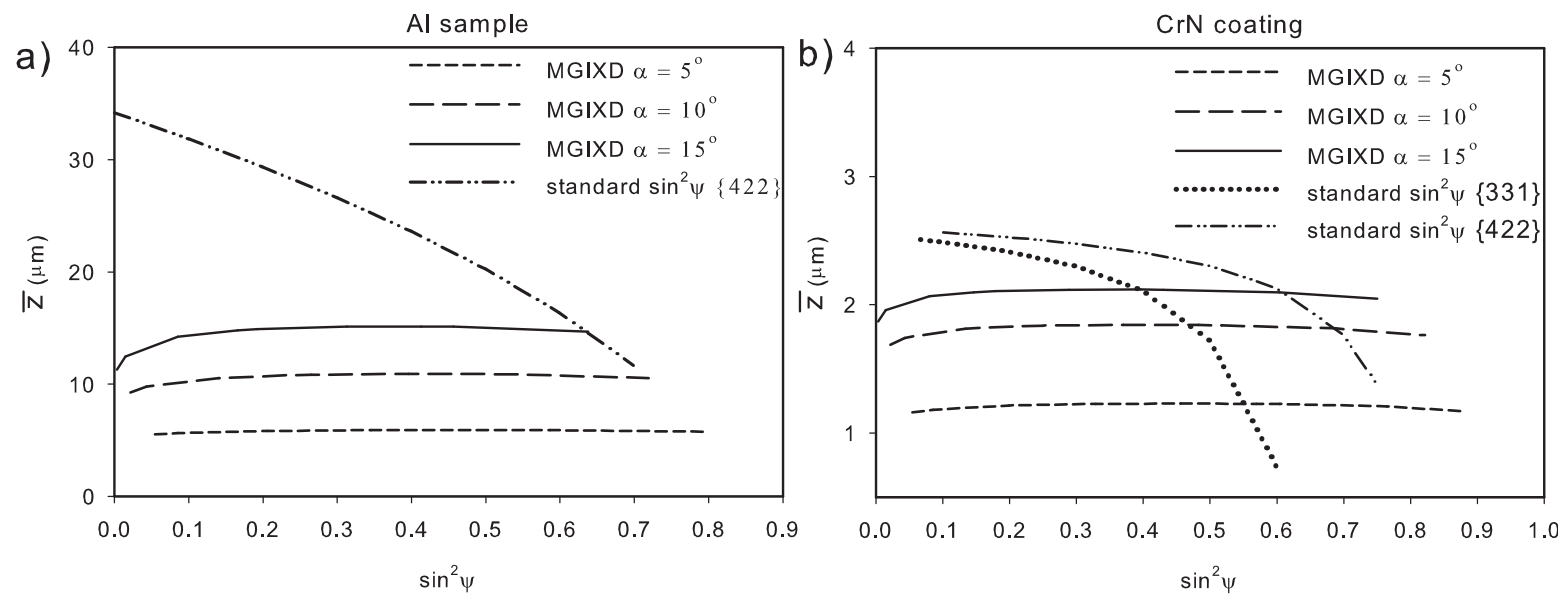

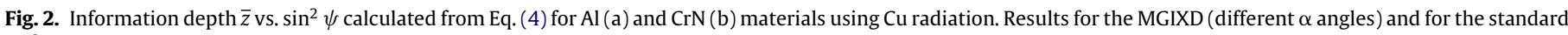

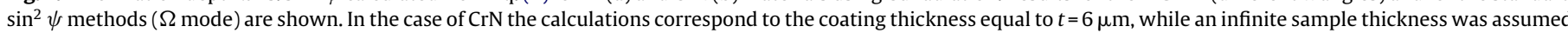
for aluminium. 
are the numbers of measured points and fitting parameters, respectively.

$$
\text { The value of } \chi^{2} \text { is a measure of goodness-of-fit, i.e. [16]: }
$$

- $\chi^{2}=1$ means that the "good fit" was obtained (it corresponds to the fitting exactly within the limits of experimental uncertainty),

- $\chi^{2}<1$ the uncertainties of experimental data $\delta_{n}\left(\langle a(\phi, \psi)\rangle_{\{h k l\}}\right)$ are overestimated,

- $\chi^{2}>1$ the uncertainties of experimental data are underestimated or calculated (theoretical) values $\left\langle a\left(\phi_{n}, \psi_{n}\right)\right\rangle_{\{h k l\}}^{c a l}$ depending on stress factors $F_{i j}(h k l, \phi, \psi)$ according to Eq.(6) are not accurate.

\section{Experimental setup}

X-ray stress determination requires a precise measurement of diffracted peak positions. A perfectly collimated (parallel) beam radically decreases errors of the determined peak position, caused by a sample misalignment. Watkins et al. showed that parallel beam optics significantly improves data quality, allowing for accurate residual stress measurements [17]. In the present work, grazing incidence X-ray diffraction measurements were carried out with XPert Philips X-ray diffractometer ( $\mathrm{Cu} \mathrm{K}_{\alpha}$ radiation) equipped with a Göbel mirror, in the incidence beam optics (Fig. 3). The experiment was repeated for various incidence angles $\alpha$ corresponding to different information depths $\bar{z}$ (see Eq. (2)). To verify the results of grazing incidence measurements, the standard $\sin ^{2} \psi$ method in $\Omega$ mode was also applied. Due to variations of information depth with the $\psi$ angle, only approximated average values of $\bar{z}$ were estimated in the standard method.

In order to test the experimental setup, a set of preliminary measurements was performed for the Al powder using two configurations, i.e., the Göbel mirror (divergence $0.02^{\circ}$ ) and a slit with a divergence of $1 / 2^{\circ}$ for the primary optics. In both cases a parallel plate collimator (Soller collimator with divergence of $0.18^{\circ}$ ) was used in the reflected beam optics. In this case the $\langle a(\phi, \psi)\rangle_{\{h k l\}}$ vs. $\sin ^{2} \psi$ plots were measured for $\phi=0^{\circ}$ and different incident angles $\alpha$. The stress values determined using the least square method (based on Eqs. (6) and (8)) are given in Table 2, while the corresponding $\langle d(\phi, \psi)\rangle_{\{h k l\}}$ vs. $\sin ^{2} \psi$ plots are shown in Fig. 4 . In the analysis, the stress factors $F_{i j}(h k l, \phi, \psi)$ were calculated from single crystal elastic constants (Table 1) assuming random orientations of powder grains.

In the analysis of experimental data it is important to take the different sensitivity of the measured lattice strain on the value of scattering angle $2 \theta_{\{h k l\}}$ into account. In this work the fitting procedure was based on Eq. (8), in which the uncertainty of equivalent lattice parameters $\delta_{n}\left(\langle a(\phi, \psi)\rangle_{\{h k l\}}\right)$ are treated as the weight in the calculation of the $\chi^{2}$ value. The $\delta_{n}\left(\langle a(\phi, \psi)\rangle_{\{h k l\}}\right)$ uncertainty is calculated directly from the uncertainty of peak position $\delta_{n}\left(2 \theta_{\{h k l\}}\right)$, i.e.:

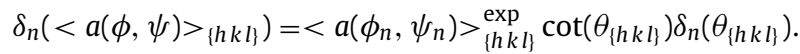

In the data analysis it can be assumed that that the $\delta_{n}\left(2 \theta_{\{h k l\}}\right)$ uncertainty is equal to the standard deviation of the peak position obtained from procedure of peak adjustment. However, these values are very small (smaller than $0.01^{\circ}$ ) and other experimental errors play a more significant role, for example those due to the misfit of the sample position, defocusing or misalignment errors. Errors having different reasons are in fact unknown, therefore we decided to assume a reasonable value of peak position uncertainty, the same for all reflections. As shown in Fig. 4 (see error bars) the values of $\delta_{n}\left(\langle a(\phi, \psi)\rangle_{\{h k l\}}\right)$, calculated using Eq. (9) with $\delta_{n}\left(2 \theta_{\{h k l\}}\right)=0.01^{\circ}$, are different for different $2 \theta_{\{h k l\}}$. This ensures different influences of measured equivalent parameters $\left\langle a\left(\phi_{n}, \psi_{n}\right)>_{\{h k l\}}^{\exp }\right.$ on the fitting quality criterion (Eq. (8)) and consequently on the values of the determined stresses. As seen in Fig. 4 the uncertainties $\delta_{n}(<a(\phi$, $\psi)>_{\{h k l\}}$ ) are larger for lower a value of $2 \theta_{\{h k l\}}$ scattering angle, i.e., the low $2 \theta_{\{h k l\}}$ angle reflections affect the fitting results less than those for which the scattering angle is higher (cf. Eq. (8)). It is also important to estimate the uncertainty of the determined stresses in the case of unknown the $\delta_{n}\left(2 \theta_{\{h k l\}}\right)$ values. Therefore, regardless of the reasons of the experimental errors or inaccuracy of the data treatment the stress uncertainties were calculated assuming a "good fit" for which $\chi^{2}=1$ [16] (in this aim the assumed uncertainty $\delta_{n}\left(2 \theta_{\{h k l\}}\right)$ was varied in order to obtain condition $\left.\chi^{2}=1\right)$.

The values of $\sigma_{11}$ stress component determined for the Al powder are compared for the two optics used. Moreover, the data treatment was repeated applying two different conditions, i.e., using all measured reflections presented in Fig. 4 or excluding two low $2 \theta$ reflections $\left\{\begin{array}{llll}1 & 1 & 1\end{array}\right\}$ and $\left\{\begin{array}{lll}2 & 0 & 0\end{array}\right\}$, for which $\left\langle a\left(\phi_{n}, \psi_{n}\right)>_{\{h k l\}}^{\exp }\right.$ deviate significantly from the theoretical values. The results of the analysis are presented in Table 2 . Small, but significant, values of fictitious stresses (between -8 and $-33 \mathrm{MPa}$ ) were found, when the slit was used. As the real stress for the powder sample is equal to zero, the determined non-zero stresses can be treated as the values of systematic uncertainty caused by the diffractometer or sample misalignments. The latter uncertainties can be minimized using parallel optics of the incident beam. The near zero values of stresses measured in the Al powder (absolute values lower $5 \mathrm{MPa}$, see Table 2) show that the experimental errors were significantly reduced by use of the Göbel mirror.

Comparing the results obtained with and without two low $2 \theta$ reflections (i.e. $\{111\}$ and $\{200\}$ ) it can be stated that a small improvement of the results (lower fictitious stress and its uncertainty) was obtained when the latter reflections were excluded (Table 2). However, the difference is not significant because in our data treatment the influence of the $\left\langle a\left(\phi_{n}, \psi_{n}\right)\right\rangle_{\{h k l\}}^{\exp }$ values on the fitting results decreases with the $2 \theta$ angle. Therefore in the further analysis even the data obtained with the low $2 \theta$ angle will be used, certainly with definitely smaller weight (Eqs. (8) and (9)).

For comparative purposes the results of standard $\sin ^{2} \psi$ method ( $\Omega$ mode, 422 reflection) are also shown in Table 2 . In this case, a small value of uncertainty (less than $5 \mathrm{MPa}$ ) was obtained for both experimental setups.

\section{Residual stress measurements}

The diffractometer equipped with the Göbel mirror was used to measure residual stresses in two very different types of samples, i.e. in the mechanically treated surface of an Al-Mg alloy [15] and in a $\mathrm{CrN}$ coating deposited at high temperature on a $4 \mathrm{H} 13$ steel substrate [7]. As shown in Table 1, the first material exhibits a very low anisotropy of single crystal elastic constants, i.e. the Zener factor A is close to 1 for aluminium (due to the low contents of magnesium, shown in Table 3, the Al elastic constants were used for the $\mathrm{Al}-\mathrm{Mg}$ alloy), while the elastic properties of the CrN crystals are strongly anisotropic $(A=0.34)$. Moreover, relatively low residual stresses were generated by the mechanical treatment in the $\mathrm{Al}-\mathrm{Mg}$ samples and very high stress is expected in the $\mathrm{CrN}$ coating [20-22].

\subsection{Residual stress in Al-Mg samples}

The residual stress was measured in the $\mathrm{Al}-\mathrm{Mg}$ alloy having the chemical composition given in Table 3. The samples were prepared from a sheet that was subjected to cold rolling followed by an industrial stabilisation (in such an industrial process the annealing temperature is maintained between 50 and $200^{\circ} \mathrm{C}$ ). Next, the material was annealed at $420^{\circ} \mathrm{C}$ for $1.5 \mathrm{~h}$ in a salt bath and cooled in the air. Afterwards, a part of the material was cold rolled up to the 


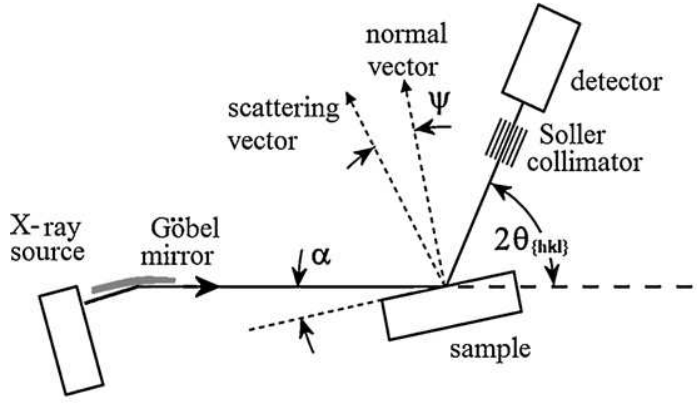

a)

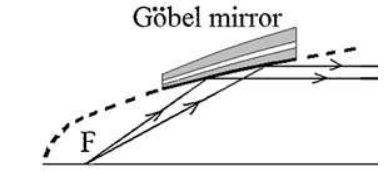

$\mathrm{X}$-ray source

in focus of parabolic

Göbel mirror (F)

b)

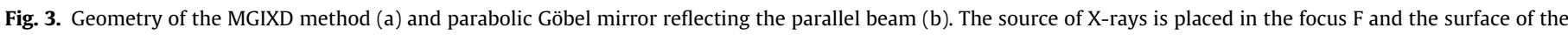
mirror consists of nanolayers monochromating the reflected beam.

Table 2

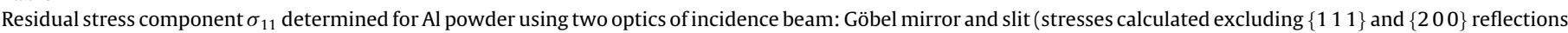
compared with results obtained from all reflections).

\begin{tabular}{|c|c|c|c|c|c|}
\hline Method & $\alpha\left[^{\circ}\right]$ and $\{h k l\}$ & information depth $\bar{z}[\mu \mathrm{m}]$ & primary beam configuration & $\sigma_{11}[\mathrm{MPa}]$ all reflections & $\sigma_{11}[\mathrm{MPa}]\left\{\begin{array}{lll}1 & 1 & 1\end{array}\right\},\left\{\begin{array}{lll}2 & 0 & 0\end{array}\right\}$ excluded \\
\hline \multirow[t]{6}{*}{ Grazing incidence } & $\alpha=5^{\circ}$ & 5.8 & Göbel mirror & $-5.0 \pm 3.0$ & $-1.6 \pm 1.5$ \\
\hline & & & Slit & $-22.1 \pm 5.3$ & $-16.0 \pm 5.3$ \\
\hline & $\alpha=10^{\circ}$ & 10.8 & Göbel mirror & $-3.1 \pm 3.2$ & $-0.4 \pm 1.1$ \\
\hline & & & Slit & $-28.1 \pm 6.4$ & $-33.3 \pm 5.6$ \\
\hline & $\alpha=15^{\circ}$ & 14.9 & Göbel mirror & $-3.0 \pm 4.4$ & $-0.4 \pm 3.8$ \\
\hline & & & Slit & $-7.3 \pm 6.1$ & $-8.6 \pm 7.3$ \\
\hline \multirow[t]{2}{*}{ Standard } & $\{422\}$ & $12-34$ & Göbel mirror & $-2.1 \pm 0.5$ & \\
\hline & & & Slit & $-0.5 \pm 1.4$ & \\
\hline
\end{tabular}

reduction of $92 \%$. Finally, the surfaces of the not rolled (specimen A) and rolled (specimen B) samples were mechanically polished by hand polishing device ESC 200 GTL - ESCIL and emery papers from 240 to 4000 grit, with 5 steps $(240 ; 320 ; 600 ; 1200 ; 4000$ grit). The surface preparation that was done is a standard laboratory treatment before corrosion analyses [15,23]. In industrial processes polishing is used before some surface treatments as anodization [23].

The average roughness parameters were similar for both samples and equal to approximately $R_{\mathrm{a}}=0.4 \mu \mathrm{m}$. For both samples the orientation distribution function (ODF [24]) characterizing crystallographic texture was determined from pole figures $\left\{\begin{array}{lll}1 & 1 & 1\end{array}\right\},\left\{\begin{array}{lll}2 & 0 & 0\end{array}\right\}$

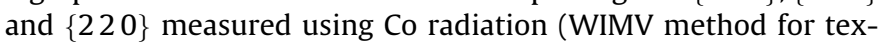
ture analysis was used [25]). The ODFs for initial sample (A) and cold rolled sample (B) are shown in Fig. 5.

The MGIXD and the standard $\sin ^{2} \psi$ methods with parallel optics (Göbel mirror) were used to determine residual stresses in the Al$\mathrm{Mg}$ alloy samples. The measurements were done for two directions $\left(\phi=0^{\circ}\right.$ and $\phi=90^{\circ}$, see Fig. 1a) and for two incidence angles $\left(\alpha=5^{\circ}\right.$ and $\alpha=15^{\circ}$ ). Sample diffraction patterns obtained for the A and B samples $\left(\alpha=5^{\circ}\right)$ are shown in Fig. 6 . The positions of the peaks were determined by fitting pseudo-Voigt functions to the experimental diffraction peaks. Using the Bragg relation and Eq. (5) the equivalent lattice parameters $\langle a(\phi, \psi)\rangle_{\{h k l\}}$ were calculated. The $\langle a(\phi, \psi)\rangle_{\{h k l\}}$ vs. $\sin ^{2} \psi$ plots, presented in Figs. 7 and 8, show very good quality of fitting the theoretical relations to the experimental data.

In the calculations of the stress factors $F_{i j}(h k l, \phi, \psi)$, the ODFs shown in Fig. 5 and the single crystal elastic constants of aluminium (Table 1) were used [3]. It should be noted that in the case of low anisotropy of the crystal elastic properties $(A=1.22$, Table 1$)$ the $F_{i j}(h k l, \phi, \psi)$ factors do not depend significantly on the $h k l$ reflections and on the crystallographic texture. Hence, the $\langle a(\phi, \psi)\rangle_{\{h k l\}}$ vs. $\sin ^{2} \psi$ plots obtained using the MGIXD method are almost linear (similarly as for the standard $\sin ^{2} \psi$ method, when only one reflection is used).

Two stress components, $\sigma_{11}$ (along the rolling direction) and $\sigma_{22}$ (along the transverse direction), were determined for the depths of $5.8 \pm 0.2 \mu \mathrm{m}$ and $14.2 \pm 2.0 \mu \mathrm{m}$ in the case of the MGIXD method and for the approximate depth between 12 and $34 \mu \mathrm{m}$ in the case of the standard $\sin ^{2} \psi$ method (cf. ranges of information depth shown in Fig. 2a). The in-depth distributions of the stress below the sample surface are shown in Fig. 9. It should be stated, that in spite of its low spatial accuracy (large horizontal error bars for last points in Fig. 9), the results of the standard $\sin ^{2} \psi$ method measurements confirm the in-depth profile of stress distributions determined by the MGIXD method.

Additionally, the diffraction peak profile was also analyzed for $\mathrm{Al}-\mathrm{Mg}$ samples. It is well known that the peak position is determined by macrostresses, while its broadening depends on the density and structure of the defects inside polycrystalline grains $[4,13,14,26]$. The comparison of the diffraction peaks (Fig. 6) shows a low density of dislocation, i.e., narrow peak profiles, in the initial sample (A), while broad profiles were measured for cold rolled one (B; see Fig. 6). The advantage of the presented MGIXD method is that diffraction peaks were measured for different reflections at a given $\alpha$ angle corresponding to a constant information depth. Thus the quantitative analysis of the lattice strains caused by the lattice defects can be performed. In this work the Williamson-Hall method

Table 3

Chemical composition of aluminium alloy AA5083.

\begin{tabular}{|c|c|c|c|c|c|c|c|c|c|}
\hline Element & $\mathrm{Mg}$ & $\mathrm{Fe}$ & $\mathrm{Si}$ & $\mathrm{Mn}$ & $\mathrm{Cr}$ & $\mathrm{Zn}$ & $\mathrm{Ti}$ & $\mathrm{Cu}$ & Other \\
\hline Concentration (\%) & $4.0-4.9$ & 0.4 & 0.4 & $0.3-1.0$ & $0.25-0.5$ & 0.25 & 0.15 & 0.1 & 0.15 \\
\hline
\end{tabular}



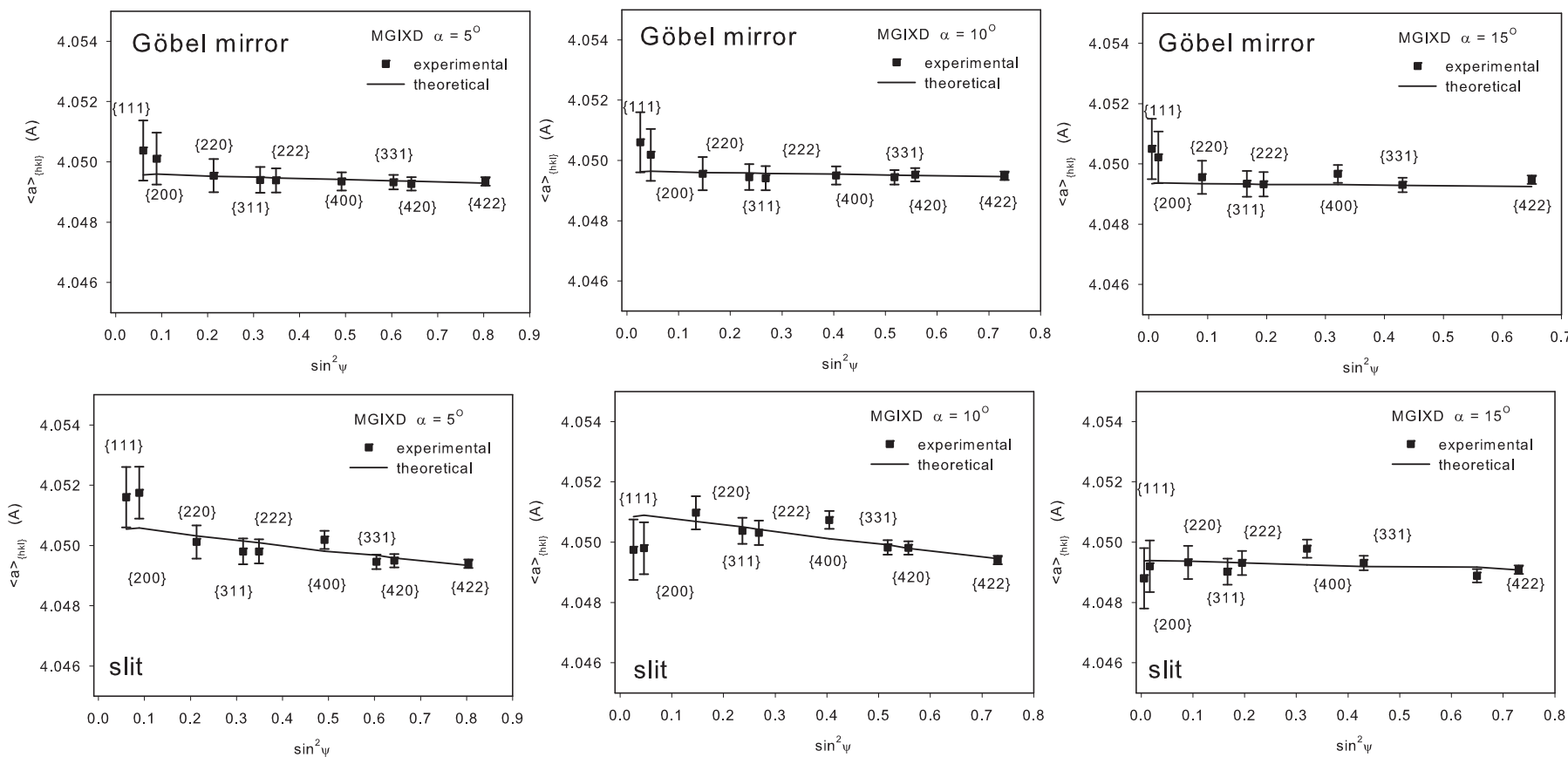

a)
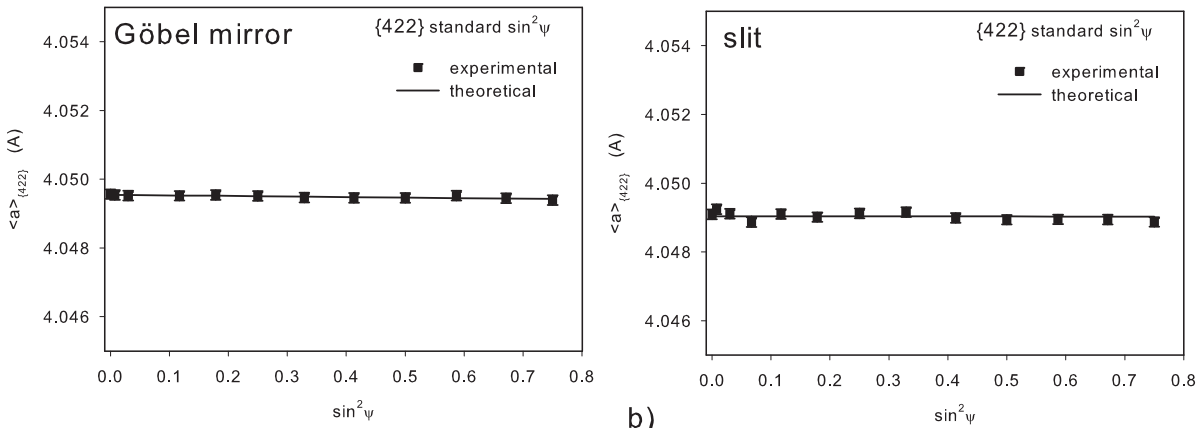

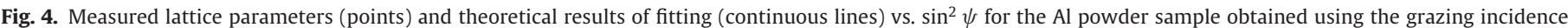

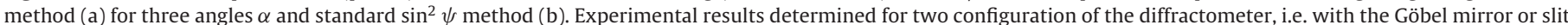
in the incident beam optics are shown.

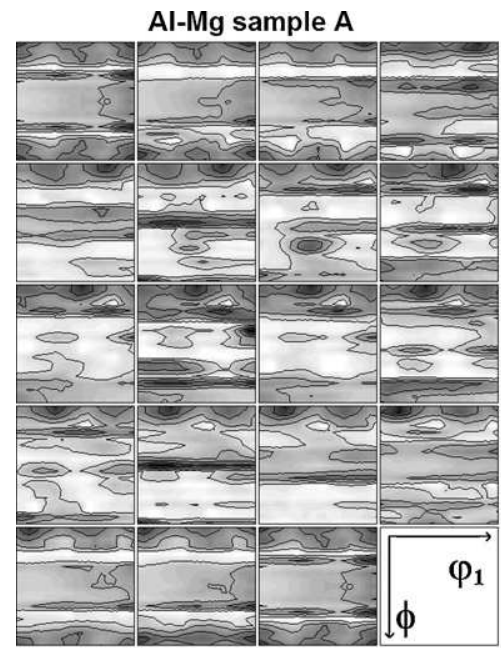

a)

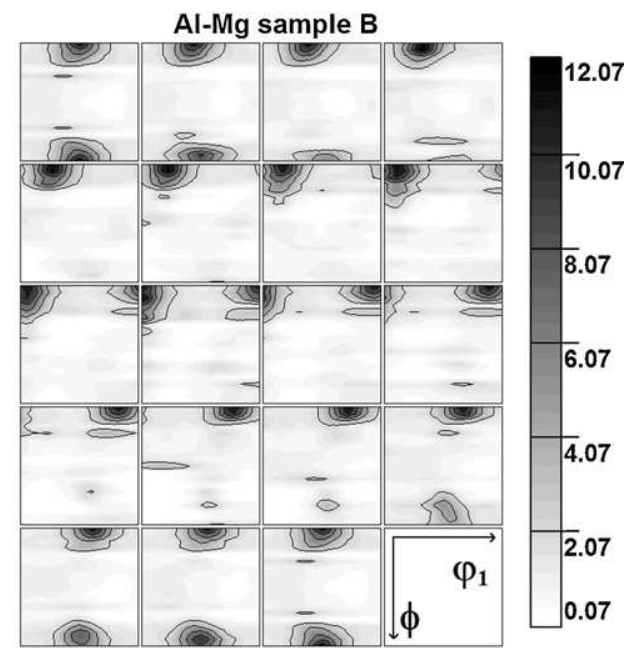

b)

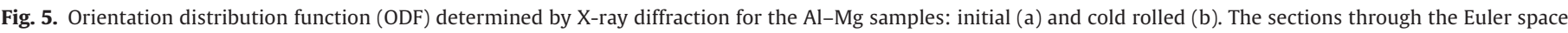
[20] with the step of $5^{\circ}$ along the $\phi_{2}$ axis are presented. 

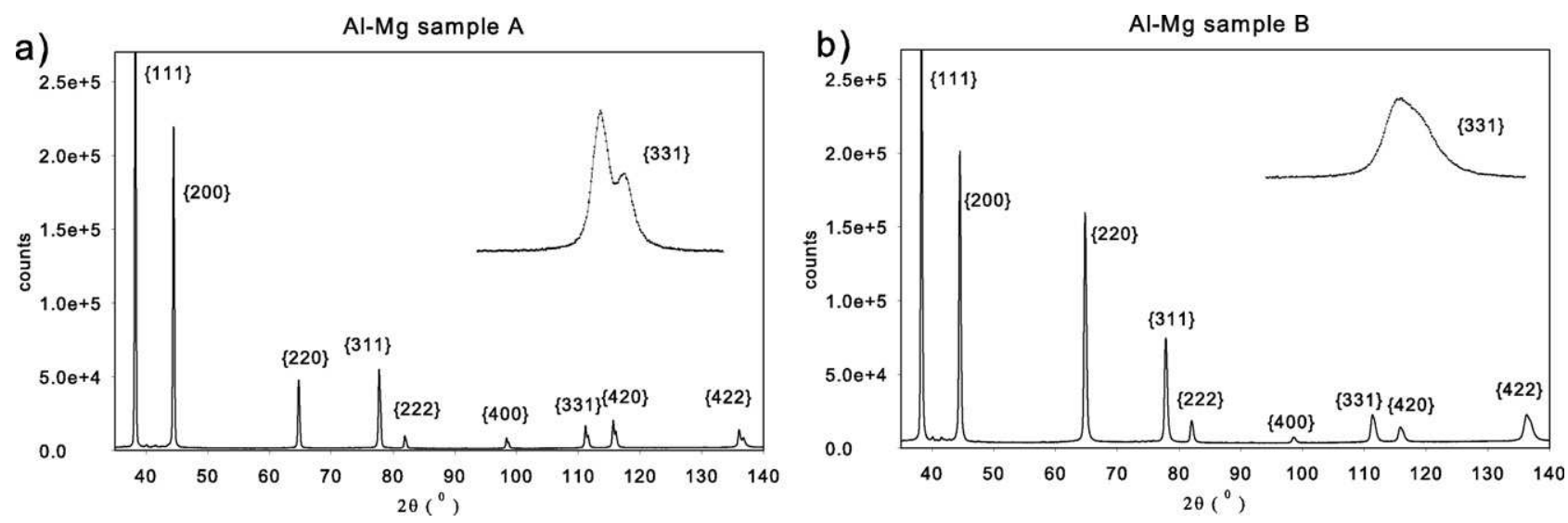


into $K_{\alpha 1}$ and $K_{\alpha 2}$ lines is visible) in comparison with the cold rolled sample B.

$[13,14]$ was applied to determine the root mean square value of the third order strain $\sqrt{\left\langle\varepsilon_{\text {III }}^{2}\right\rangle}$ characterizing the distortion of the lattice within grains $[4,13,14,26]$. As shown in Table 4 , the value of $\sqrt{\left\langle\varepsilon_{\text {III }}^{2}\right\rangle}$ for the cold rolled sample (B) does not depend on the depth. In the case of initial sample (A) the root mean square of the third order strain cannot be determined because its contribution to the peak broadening is too small in comparison with instrument peak broadening.

The following conclusions concerning stress fields in different Al-Mg samples can be drawn:

- nearly isotropic planar stresses (i.e., $\sigma_{11}=\sigma_{22}$ ) were found in the polished initial sample (A), while $\sigma_{11} \neq \sigma_{22}$ occurred in the cold rolled and the polished sample $(B)$,

- the initial sample (A) exhibits a significant in-depth gradient of stress characteristic for polished surfaces, while the approximately constant stress was determined in the cold rolled and polished sample (B),

- the cold rolling process introduced a significant change in the microstructure of the material causing significant distortion of the lattice within the grains (described by $\sqrt{\left\langle\varepsilon_{I I I}^{2}\right\rangle}$, which can be attributed to the lattice defects, mainly dislocations [26],

- significant texture evolution caused by the cold rolling process was observed (Fig. 5).

\subsection{Residual stress in CrN coating}

This section presents the results of the diffraction measurements of stress in the CrN film ( $6 \mu \mathrm{m}$ thickness) deposited on the $4 \mathrm{H} 13$ steel substrate. The coating was obtained by means of the arc-vacuum method in a nitrogen atmosphere at the pressure of $\mathrm{N}_{2}$ equal to $3.5 \times 10^{-2} \mathrm{mbar}$ and the temperature of $450^{\circ} \mathrm{C}$. The average speed of deposition was $60 \mathrm{~nm} / \mathrm{min}$. As a result, the coating exhibiting the average surface roughness $R_{\mathrm{a}}=0.33 \mu \mathrm{m}$ and fibre crystallographic texture (ODF determined using Co radiation is

\section{Table 4}

Root mean square of third order strain $\sqrt{\left\langle\varepsilon_{I I I}^{2}\right\rangle}$ for Al-Mg cold rolled sample B.

\begin{tabular}{lrr}
\hline$\alpha\left[^{\circ}\right]$ & Information depth $\bar{z}[\mu \mathrm{m}]$ & $\sqrt{\left\langle\varepsilon_{\text {III }}^{2}\right\rangle}[\%]$ \\
\hline 5 & $5.8 \pm 0.2$ & $0.19 \pm 0.01$ \\
15 & $14.9 \pm 2.1$ & $0.17 \pm 0.01$ \\
\hline
\end{tabular}

shown in Fig. 10) was produced. The advantage of the $\mathrm{CrN}$ film is its high hardness, good oxidation resistance and a low friction coefficient. Therefore it is used to coat cutting tools, and due to a good biocompatibility, it can be applied to medical instruments or to surfaces of joint replacements. Residual stress created during the cooling of the deposited layer to room temperature significantly influences the strength of the coating. The favourable state of stress in the film is the compressive stress that causes the closing of the initiated cracks and prevents their propagation.

Stress measurements for the CrN layer were performed using configuration with the Göbel mirror and the parallel plate collimator in the primary and secondary optics, respectively. The diffraction pattern, presented in Fig. 11 for $\alpha=5^{\circ}$ shows a large broadening of the diffraction peaks. The root mean square values of the third order strain $\sqrt{\left\langle\varepsilon_{I I I}^{2}\right\rangle}$ characterizing the distortion of the lattice within the grains, calculated using the Williamson-Hall method [13,14], are shown in Table 5 (cf. [27]). The values of $\sqrt{\left\langle\varepsilon_{I I I}^{2}\right\rangle}$ are much larger than in the case of the cold rolled $\mathrm{Al}-\mathrm{Mg}$ alloy and they do not change vs. the information depth. The large value of third order stresses can be attributed to the high level of defects caused by high-energy ion deposition. It has been observed in [28] that the width of the diffraction peak significantly decreased due to the annealing of the similar samples.

The equivalent measured and theoretical lattice parameters lattice $\langle a(\phi, \psi)\rangle_{\{h k l\}}$ vs. $\sin ^{2} \psi$ for $\alpha=5^{\circ}, 10^{\circ}$ and $15^{\circ}$ are shown in Fig. 12. Due to the process symmetry, an isotropic planar stress state (i.e., $\sigma_{11}=\sigma_{22}$ ) was assumed and the measurements were performed only in one direction. The stress factors $F_{i j}(h k l, \phi, \psi)$ were calculated using the single crystal elastic constants of $\mathrm{CrN}$ (Table 1) and the ODF shown in Fig. 10. It can be noticed that a high anisotropy of crystal elastic constants $(A=0.34$, Table 1$)$ caused significant nonlinearities of the $\langle a(\phi, \psi)\rangle_{\{h k l\}}$ vs. $\sin ^{2} \psi$ plots. Using our methodology of data analysis based on Eq. (6) (where $F_{i j}(h k l, \phi, \psi)$ factors are calculated for different $h k l$ reflections) the experimental points are matched by the fitted data (lines). It can be concluded

Table 5

Root mean square of third order strain $\sqrt{\left\langle\varepsilon_{I I I}^{2}\right\rangle}$ for CrN coating.

\begin{tabular}{lcc}
\hline$\alpha\left[^{\circ}\right]$ & Information depth $\bar{z}[\mu \mathrm{m}]$ & $\sqrt{\left\langle\varepsilon_{I I I}^{2}\right\rangle}[\%]$ \\
\hline 5 & $1.17 \pm 0.01$ & $0.41 \pm 0.06$ \\
10 & $1.73 \pm 0.04$ & $0.49 \pm 0.05$ \\
15 & $2.00 \pm 0.05$ & $0.43 \pm 0.08$ \\
\hline
\end{tabular}


SAMPLE A

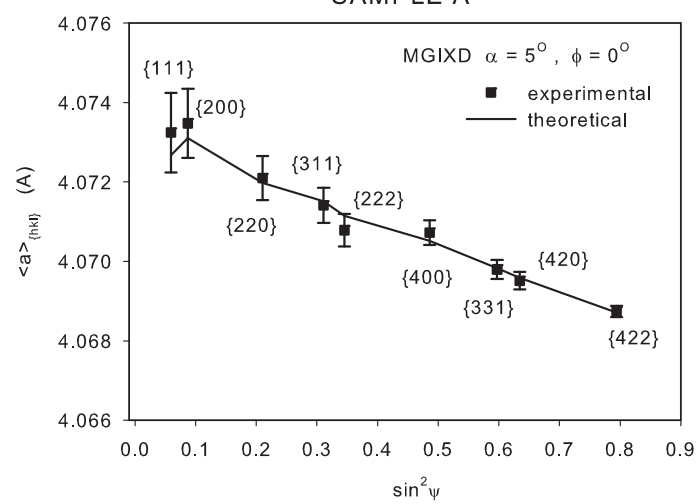

SAMPLE A



SAMPLE B

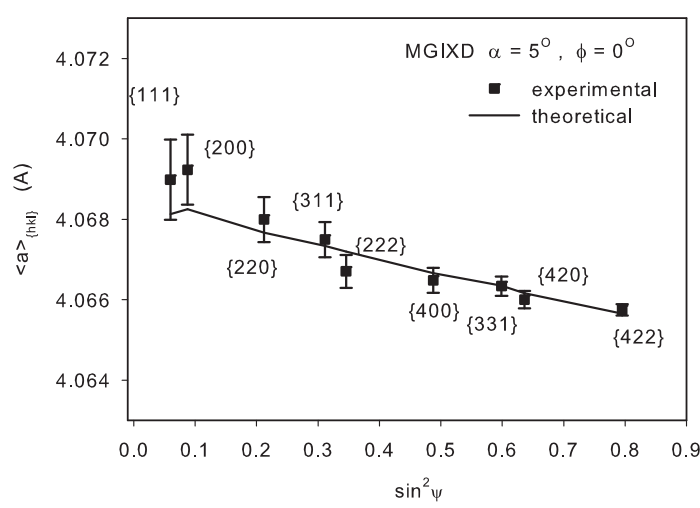

SAMPLE B

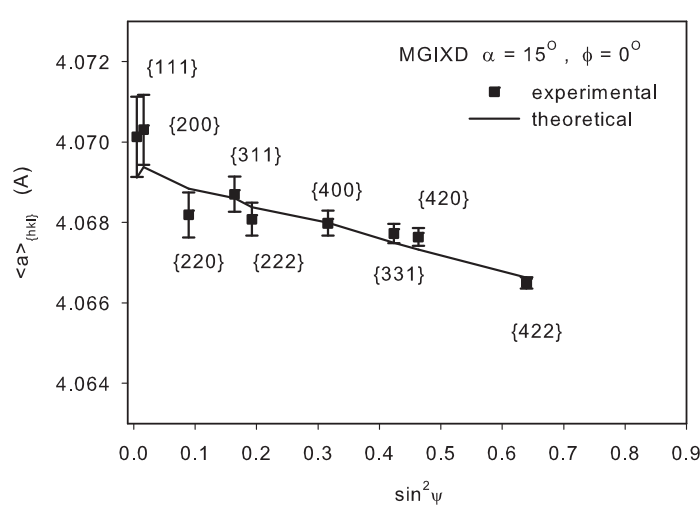

SAMPLE A

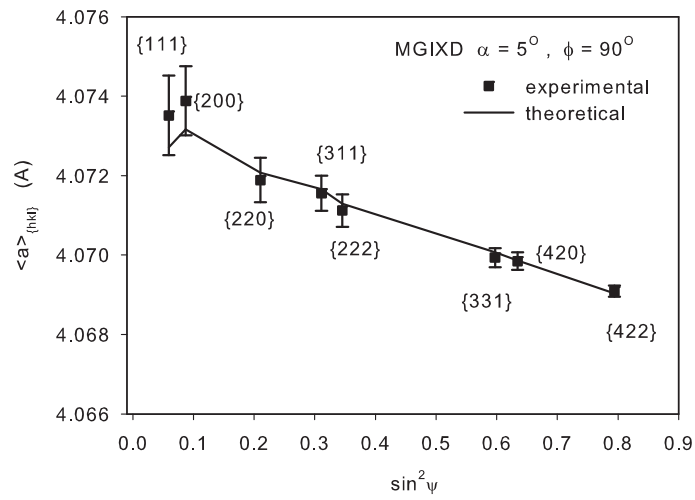

SAMPLE A

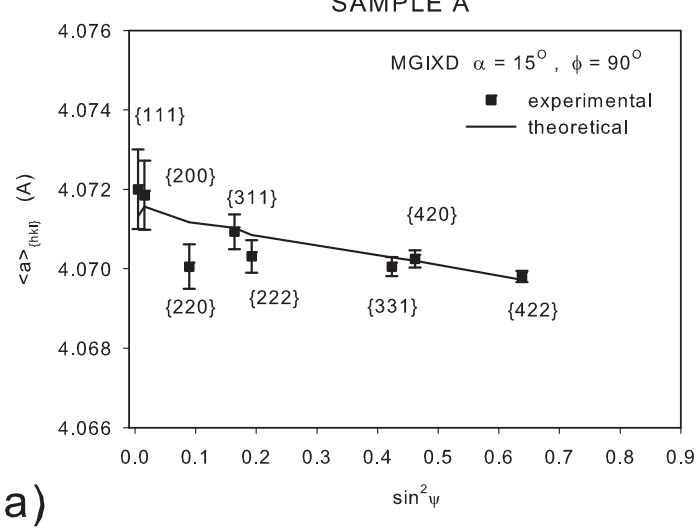

SAMPLE B

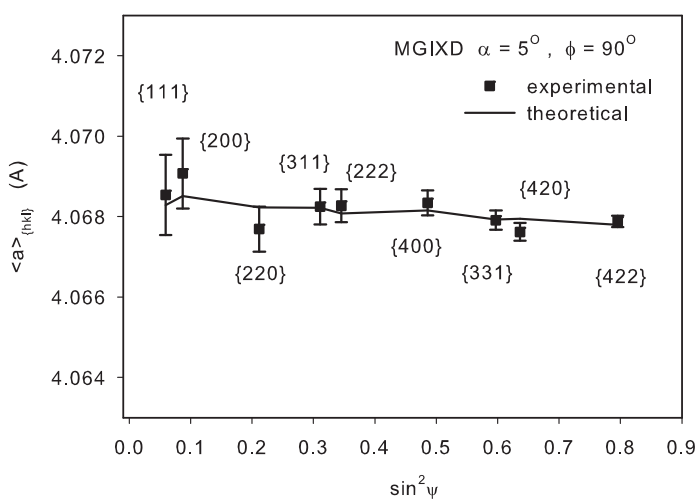

SAMPLE B



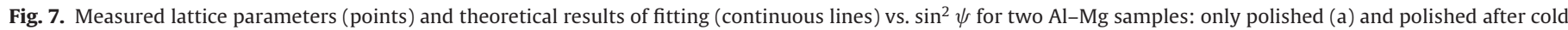
rolling (b). Results of the grazing incidence method for two angles $\alpha$ and two $\phi$ directions are shown. 
SAMPLE A

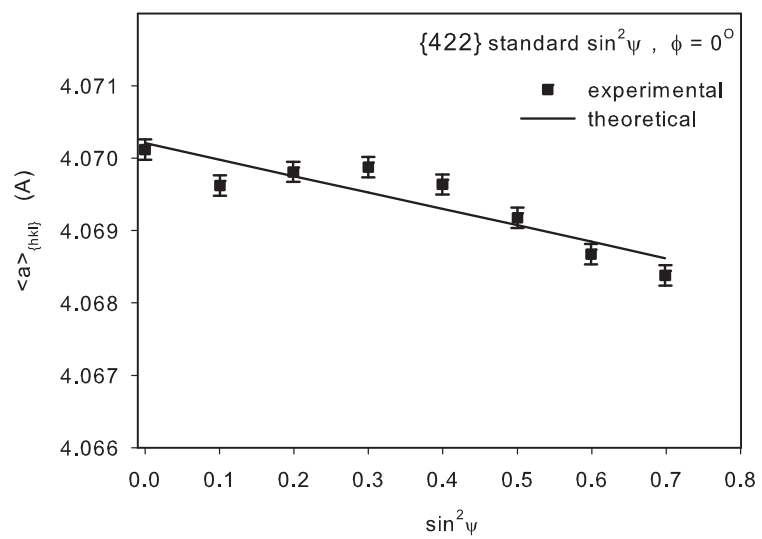

a)
SAMPLE B

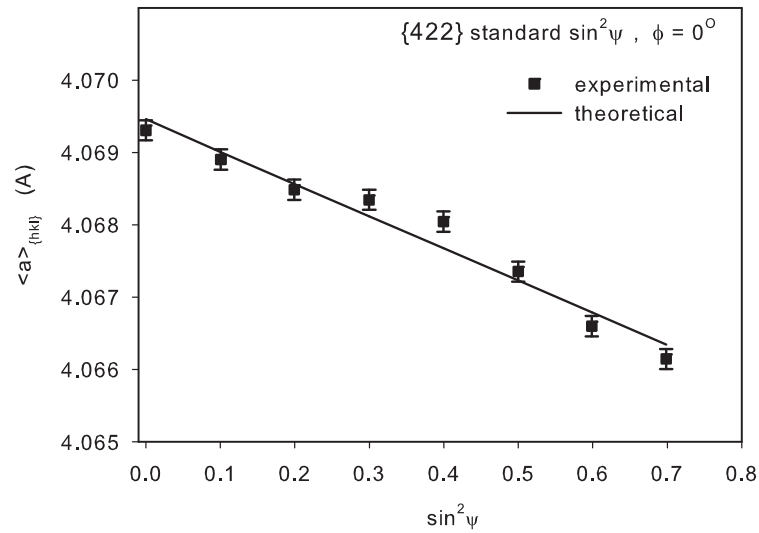

b)

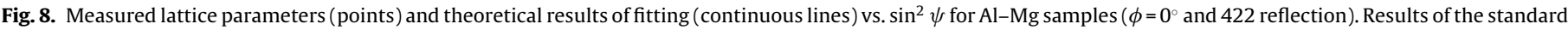
$\sin ^{2} \psi$ method are shown for only polished (a) and polished after cold rolling (b) specimens.
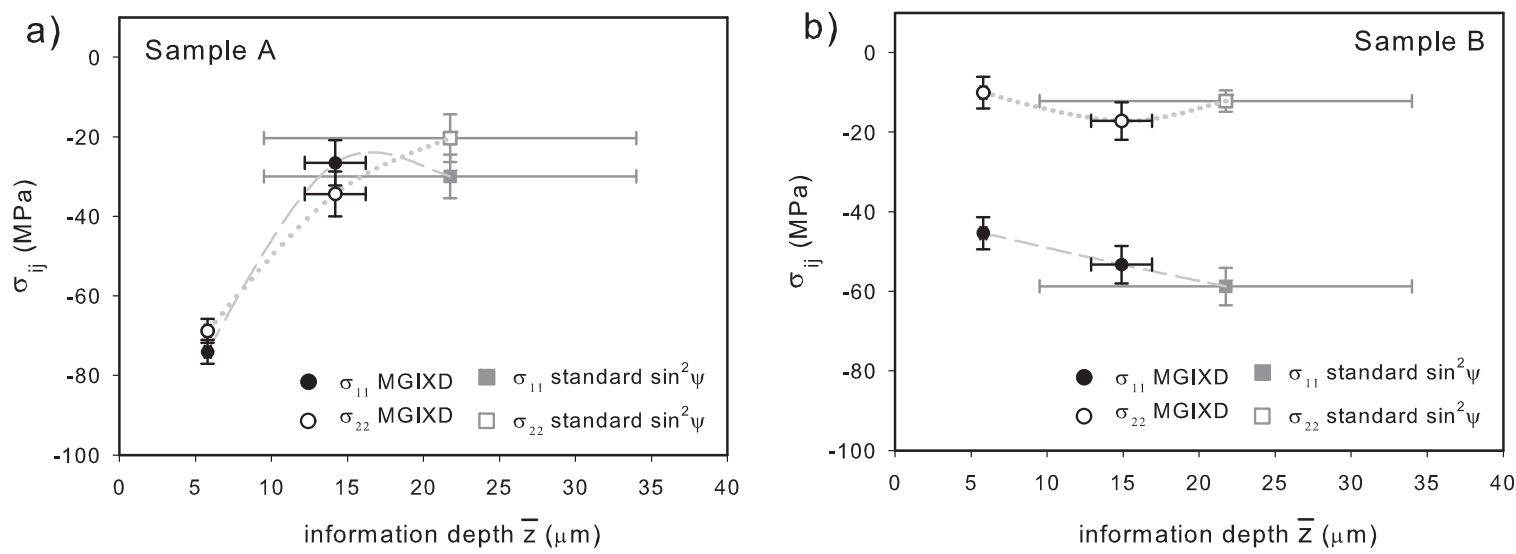

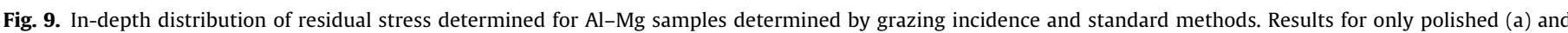
polished after cold rolling (b) specimens are shown.

\section{CrN}
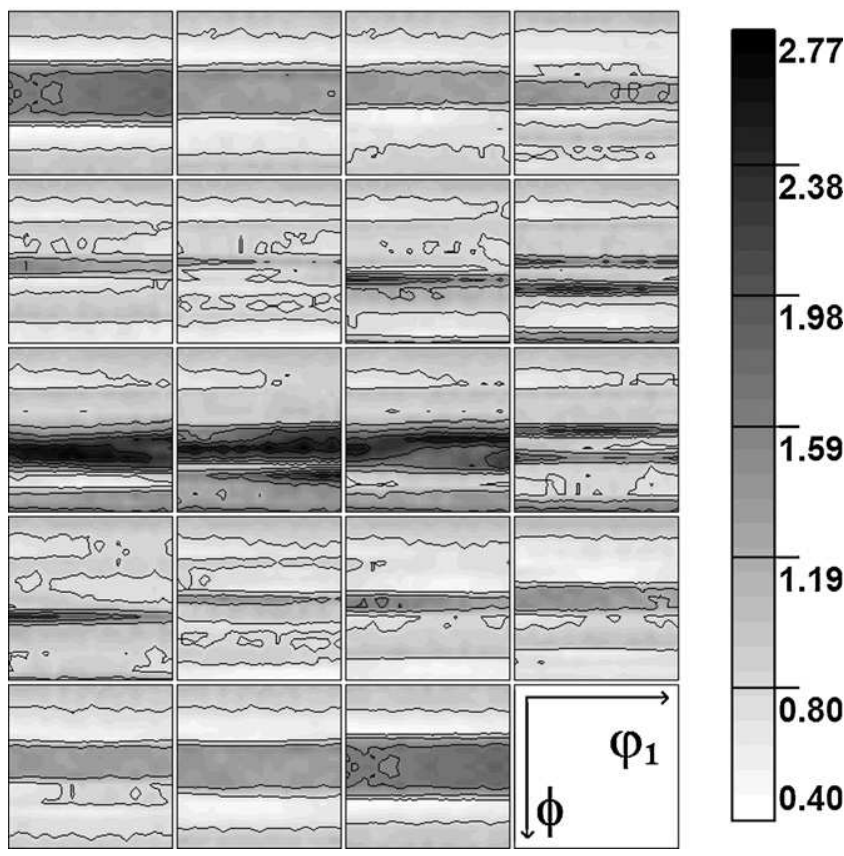

Fig. 10. Orientation distribution function (ODF) for $\mathrm{CrN}$ coating determined by $\mathrm{X}$ ray diffraction. The sections through Euler space [20] with the step of $5^{\circ}$ along $\phi_{2}$ axis are presented.



Fig. 11. Diffractogram for the studied CrN coating (MGIXD with incident angle $5^{\circ}$ ). Large diffraction peak broadening is shown for the 422 reflection. 

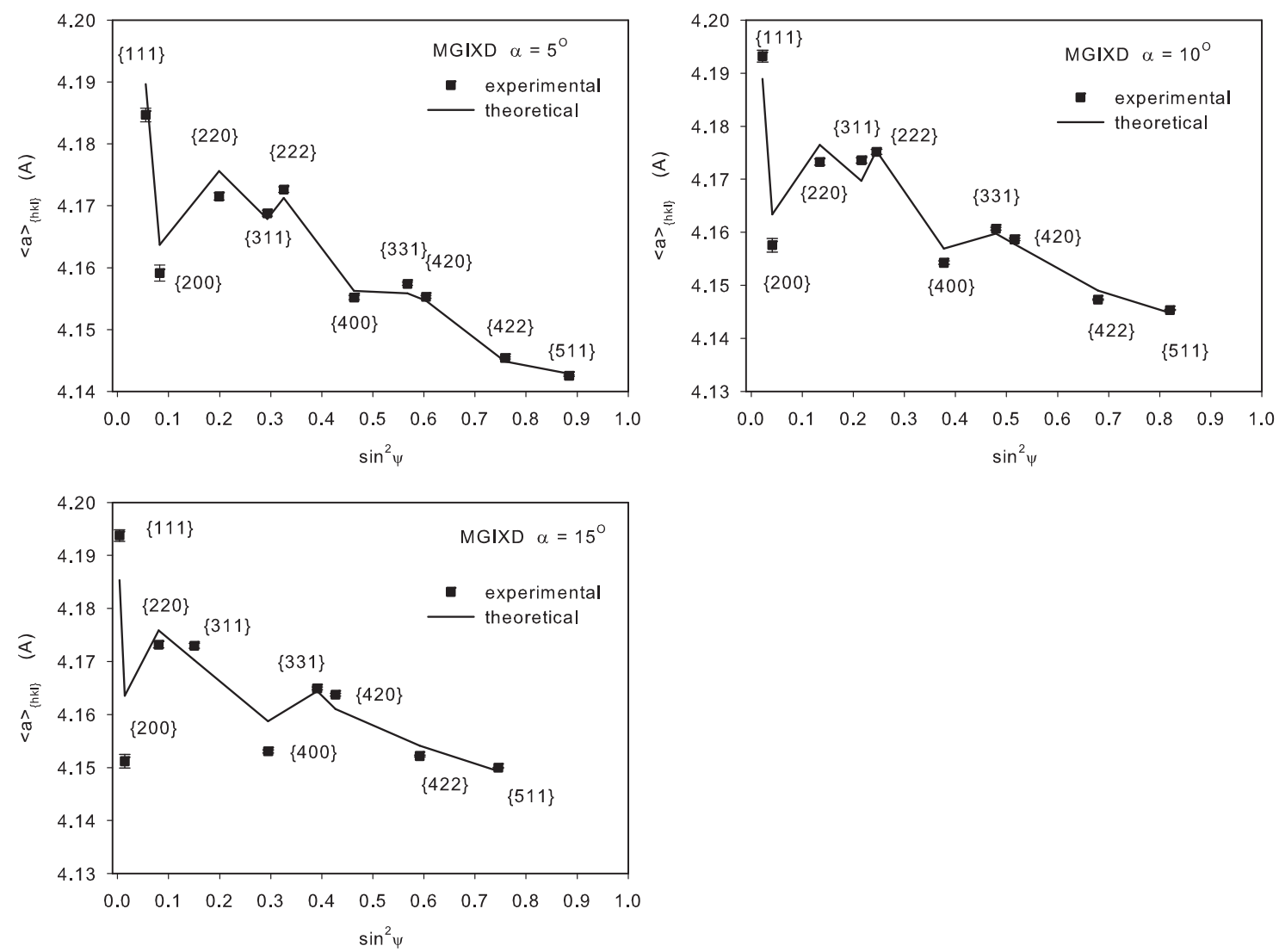

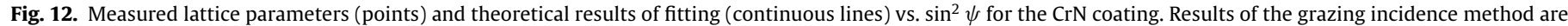
shown for three angles $\alpha$.

that the elastic anisotropy of the material was properly taken into account. Additionally, the standard diffraction measurements were performed using 311 and 422 reflections. As shown in Fig. 13, the linear nature of the $\langle a(\phi, \psi)\rangle_{\{h k l\}}$ vs. $\sin ^{2} \psi$ plot was obtained in both measurements.

A high compressive stress, with a relatively small variation vs. depth, was found in the CrN coating (Fig. 14). The stresses obtained using the MGIDX and standard methods are very similar, however in the standard method it is not possible to precisely determine the depth for which the stress is measured (large horizontal error bars). Our measurements reveal a large compressive stress in the $\mathrm{CrN}$ layer. It results from different shrinking amplitudes of the $\mathrm{CrN}$ layer and the steel substrate during cooling (their thermal expansion coefficients are: $\alpha_{\mathrm{CTE}}=6 \times 10^{-6} \mathrm{~K}[29]$ and $\alpha_{\mathrm{CTE}}=11-12 \times 10^{-6} \mathrm{~K}$ for steel substrate and for $\mathrm{CrN}$ coating, respectively $[20,21])$. It should be noted that the observed important compressive stress is caused not only by the temperature effect but also due to the peening of the growing coating by accelerated atoms, interdiffusion and the reactions with the substrate $[21,28]$. A similar level of the stresses in the $\mathrm{CrN}$ coating deposited on the steel base was previously observed in $[7,21,28]$. As already mentioned, this stress state enhances the fracture resistance and the strength of the coating.
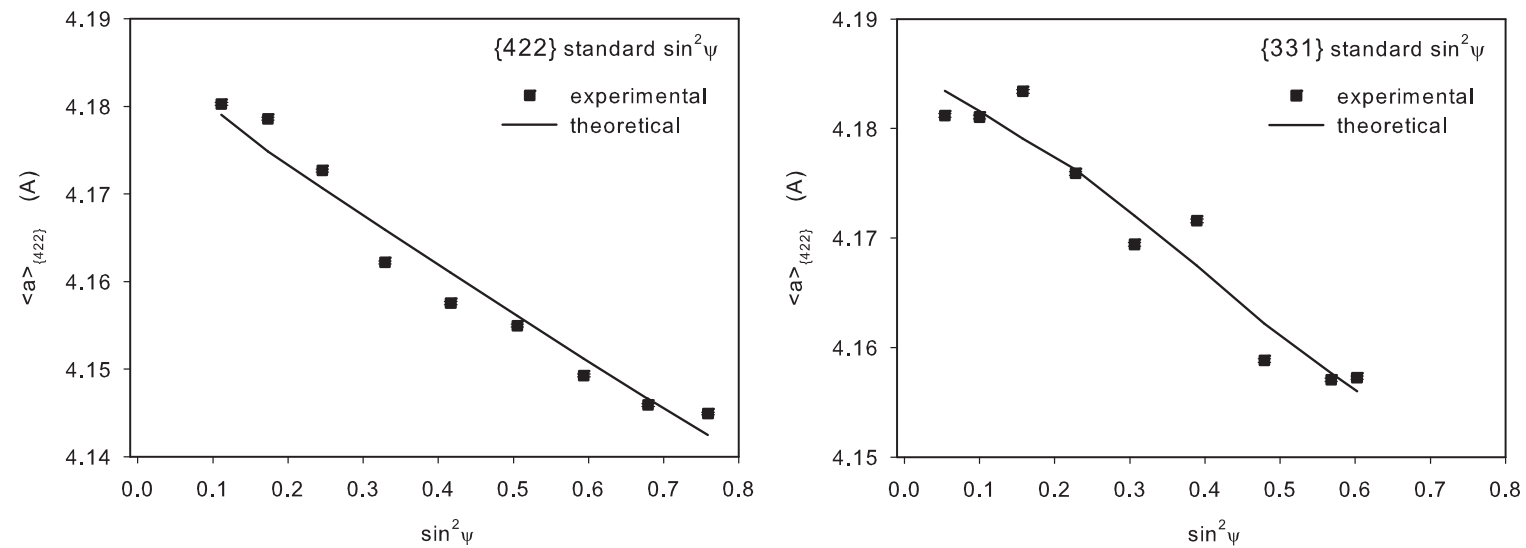


for 311 and 422 reflections. 


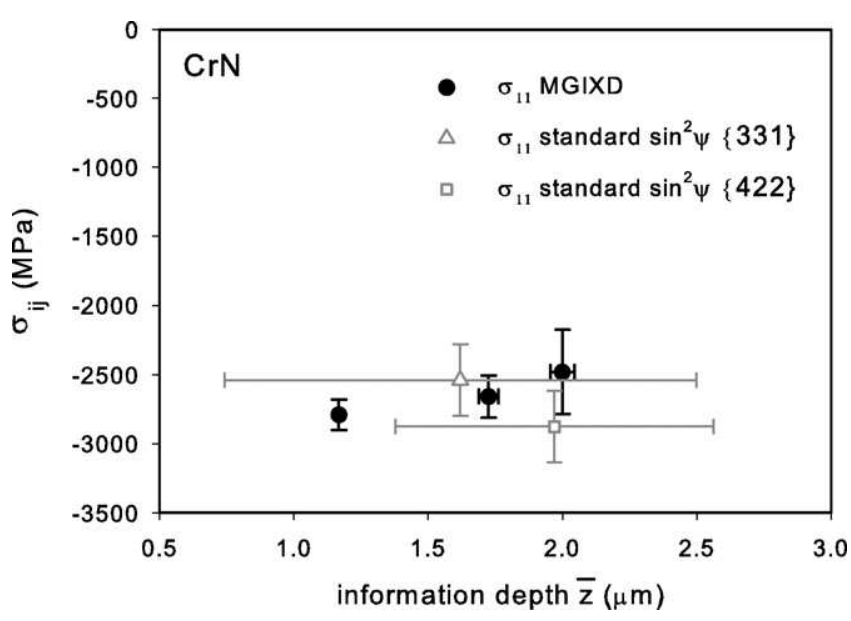

Fig. 14. In-depth distribution of residual stress determined for $\mathrm{CrN}$ coating determined by grazing incidence and standard methods.

\section{Discussion and general conclusions}

The multi-reflection method of the experimental data analysis was used for the determination of residual stresses using the multireflection grazing incidence geometry (the MGIDX method). In this technique the interplanar spacings $\langle d(\phi, \psi)\rangle_{\{h k l\}}$ are measured for different orientations of the scattering vector. The stress state can be determined for a chosen material layer, at a given distance below the sample surface, which can be changed easily. In contrast, in the standard $\sin ^{2} \psi$ method the depth of measurement is not strictly determined, because it changes during measurement (large horizontal error bars in Figs. 9 and 14). This method is not applicable for the analysis of in-depth stress heterogeneity if additional assumptions are not introduced.

Using parallel beam optics it was possible to increase the accuracy of the lattice strain measurements by X-ray radiation. The analysis of the experimental results performed in this work for the powder sample proved that the Göbel mirror installed in the primary optics of diffractometer can significantly reduce the uncertainty of the determined stresses.

It was shown that for different crystal anisotropies and various surface treatments, the multi-reflection method can be successfully applied to interpret the grazing incidence results. Both for elastically isotropic (Al-Mg alloy) and strongly anisotropic ( $\mathrm{CrN}$ ) crystals the $\langle a(\phi, \psi)\rangle_{\{h k l\}}$ vs. $\sin ^{2} \psi$ plots were correctly predicted, when the diffraction elastic constants were calculated by the self-consistent method used for the sample surface (the free-surface method in which the crystallographic texture is taken into account [3]).

The residual stresses, measured using the grazing incidence geometry, were completed by the standard measurements and a very good accordance of the stress was found for both methods, especially when the stress value did not change significantly with the information depth (Figs. 9b and 14). It should be stated that only MGIXD method provides a special resolution enough to observe the stress gradient (Fig. 9), while only the mean stress for large range of information depth can be obtained from the standard method.

The advantage of the multi-reflection grazing incidence method is that the diffraction peaks for many reflections are measured. Therefore not only the stresses but also the peak broadening can be analysed (using the Williamson-Hall method for example). In the present work, for the first time the macroscopic residual stress $(\sigma)$ as well as the third order lattice strain $\sqrt{\left\langle\varepsilon_{\text {III }}^{2}\right\rangle}$ (within polycrystalline grains) were determined for different information depths using the MGIXD method.
The MGIXD and the standard $\sin ^{2} \psi$ methods were applied to measure stresses in the mechanically processed $\mathrm{Al}-\mathrm{Mg}$ alloy. The results show that the stress field in the surface layer as well as the microstructure (density of dislocation) depend strongly on the sample preparation. In the case of the as received material (specimen A), mechanical polishing generated stress gradient in the surface layer, while not significant changes in microstructure were observed after this treatment. The stress components measured in two perpendicular directions are very similar. On the contrary, the stress components in the rolling and transverse directions are different and the almost constant in-depth profile of stress was found for the cold rolled sample B. Moreover, the microstructure of the rolled sample was significantly changed and a high value of $\sqrt{\left\langle\varepsilon_{\text {III }}^{2}\right\rangle}$ was found. A very high residual compressive stress, which does not change significantly with depth, was measured in the CrN coating. These results can be explained due to the difference in the shrinking of the coating and the base material during the sample cooling. Additionally, the stress is generated by the peening of the film by accelerated atoms, diffusion and the reactions processes. Moreover, a large value of the measured third order strains $\sqrt{\left\langle\varepsilon_{I I I}^{2}\right\rangle}$ in the $\mathrm{CrN}$ coating is caused by high-energy ion deposition.

\section{Acknowledgements}

The work was financed by the Polish National Centre for Science (NCN) basing on decision number: DEC-2011/01/B/ST8/07394 as well as by the Polish Ministry of Science and Higher Education (MNSiW) and its grant 3264/B/H03/2011/40.

\section{References}

[1] I.C. Noyan, J.B. Cohen, Residual Streess-Measurement by Diffraction and Interpretation, Springer-Verlag, Berlin, 1987.

[2] U. Welzel, J. Ligot, P. Lamparter, A.C. Vermeulen, E.J. Mittemeijer, Journal of Applied Crystallography 38 (2005) 1-29.

[3] A. Baczmanski, P. Lipinski, A. Tidu, K. Wierzbanowski, B. Pathiraj, Journal of Applied Crystallography 41 (2008) 854-867.

[4] Th.H. de Keijser, E.J. Mittemeijer, H.C.F. Rozendaal, Journal of Applied Crystallography 16 (1983) 309.

[5] Ch. Genzel, Physical Status Solidi A 146 (1994) 629-637.

[6] K. Van Acker, L. De Buyser, J.P. Celis, P. Von Houtte, Journal of Applied Crystallography 27 (1994) 56-66.

[7] J. Bonarski, J. Smolik, L. Tarkowski, M. Biel, Archives of Metallurgy and Materials 53 (2008) 49-55.

[8] Ch. Genzel, Materials Science and Technology 21 (2005) 10-18.

[9] Ch. Genzel, S. Krahmer, M. Klaus, I.A. Denks, Journal of Applied Crystallography 44 (2011) 1-12

[10] A. Baczmański, C. Braham, W. Seiler, N. Shiraki, Surface and Coating Technology $182(2004) 43-54$

[11] S.J. Skrzypek, A. Baczmański, W. Ratuszek, E. Kusior, Journal of Applied Crystallography 34 (2001) 427-435.

[12] M. Marciszko, A. Baczmański, M. Wróbel, W., Seiler, C., Braham, J., Donges, M. Śniechowski, K., Wierzbanowski, Thin Solid Films, (2012) in press, http://dx.doi.org/10.1016/j.tsf.2012.05.042

[13] G.K. Williamson, W.H. Hall, Acta Metallurgica 1 (1953) 22.

[14] E.J. Mittemeijer, U. Welzel, Zeitschrift für Kristallographie 223 (2008) 552-560.

[15] N. Zazi, A. Bouabdallah, O. Aaboubi, J.-P. Chopart, Journal of Solid State Electrochemistry 14 (2010) 1705-1711.

[16] W.H. Press, S.A. Teukolsky, W.T. Vetterling, B.P. Flannery, Numerical Recipes in C: The Art of Scientific Computing, second Edition, Cambridge University Press, New York, 1992

[17] T.R. Watkins, O.B. Cavin, J. Bai, J.A. Chediak, Advances in X-ray Analysis 46 (2003) 119-129.

[18] G. Simoms, H. Wang, Single Crystal Elastic Constants and Calculated Aggregate Properties: A Handbook, second edition, The M.I.T. Press, Cambridge, Massachusetts and London, 1971.

[19] M. Birkholz, Thin Film Analysis by X-ray Scattering, WILEY-VCH, Weinheim, 2006.

[20] J.G. Buijnsters, P. Shankar, W. Fleischer, W.J.P. van Enckevort, J.J. Schermer, J.J. ter Meulen, Diamond and Related Materials 11 (2002) 536-544.

[21] K.J. Martinschitz, R. Daniel, C. Mitterer, J. Keckes, Thin Solid Films 516 (2008) 1972-1976. 
[22] G.C.A.M. Janssen, F.D. Tichelaar, C.C.G. Visser, Journal of Applied Physics 100 (2006) 093512.

23] Z. Shi, G. Song, A. Atrens, Corrosion Science 48 (2006) 3531-3546.

[24] H.J. Bunge, Texture Analysis in Material Science: Mathematical Methods, Butterworth, London, 1982.

[25] J.S. Kallend, U.F. Kocks, A.D. Rollet, H.R. Wenk, Operational Texture Analysis, Raport LA-UR-90-2852, Center for Material Sciences, Los Alamos National Laboratory, USA, 1990.
[26] T. Ungár, Materials Science and Engineering A 309-310 (2001) 14-22.

[27] P. Kringhøj, J. Bøttiger, J. Chevallier, E.J. Bienk, K. Ratzke, Surface and Coatings Technology 149 (2002) 82-88.

[28] R. Lin Peng, Y.D. Wang, M. Odén, J. Almer, Materials Science Forum 490-491 (2005) 643-648.

[29] D. Gall, C.S. Shin, T. Spila, M. Oden, M.J.H. Senna, J.E. Greene, I. Petrov, Journal of Applied Physics 91 (2002) 3589. 